\title{
Report on the Course
}

At the IAU meeting in Brighton, 1970, the Executive Committee had approved the Colloquium No. 15 in Bamberg at the time of $31^{\text {st }}$ August - $3^{\text {rd }}$ September 1971, with the theme: "New Directions and New Frontiers in Variable Star Research“.

The Scientific Committee was represented by: L. Detre, O.J. Eggen, M.W. Feast, G. H. Herbig (Chairman), T.Herczeg, R. Kippenhahn, K. Kwee, F. B. Wood. The Local Organizer was W. Strohmeier.

Unfortunately $G$. H. Herbig was prevented from coming and on his request R. Kippenhahn agreed to preside the Colloquium.

The Colloquium took place in the provided time in the rooms of the Uberlandwerk Oberfranken, Bamberg, which were kindly given us at our disposal.

The number of the participants was exactly 100 , the number of the referats 60 , of them 7 were longer introductions. Greetings were sent by O. J. Eggen and B. V. Kukarkin.

Within the social events was a reception by Dr.Th. Mathleu, Oberbürgermeister of Bamberg, in the Kaisersaal of the Neue Residenz, a "Fränkischer Abend" on the Altenburg, and an invitation by the Remeis-Observatory, following the memory lecture of Cuno Hoffmeister by R. Kippenhahn (Brief Introduction in his Life), and L. Plaut (Distribution of Variable Stars within the Galaxy). Prorektor Ilschner of the University Erlangen-Nürnberg spoke welcomewords. Finally, at the end of the program was an all-day excursion to Königsberg (the native town of Regiomontan), Ebrach and Pommersfelden.

I have to thank for financial support of the Colloquium and the print of the proceedings the Bundesminister für Bildung und Wissenschaft, the Freistaat Bayern, and the Stadt Bamberg.

At the practical organization I was assisted by the staff of the Remeis-Observatory: Mrs. A. Gerneth, Messrs. R. Knigge, H. Mauder, E. Schöffel, and by the students D. Friedrich and F. M. Sosua.

W. Strohmeier

\section{Greetings by Prof. G. H. HERBIG, Lick Observatory, read by Dr. D. J.K. O'CONNELL}

I regret very much my inability personally to welcome the participants in this Colloquium on "New Directions and New Frontiers in Variable Star Research". I do want to express my deep gratitude to Professor Kippenhahn for his willingness to accept the scientific presidency of the Colloquium.

The theme of these sessions was suggested by the mounting evidence that stellar variability can no longer be regarded as a study of light curves per se, or as a private preserve of variable star specialists. Rather, variability on occassion seems most useful as an indicator that something surprising or interesting is going on: the generation of $\mathrm{X}$-ray emission, or the stimulation of the microwave lines of $\mathrm{OH}$ or $\mathrm{H}_{2} \mathrm{O}$, or the production of a vast excess of radiation in the infrared. One presumes that behind all this spectacular phenomenology lies some relatively simple truth, as for example, recognition that a particular behavior is a natural consequence of some critical phase in stellar evolution. It is our task to extricate such essential conclusions from the mass of complicated observational detail. One can readily think of areas where, in the past, this was not achieved: where progress was stifled or halted by the sheer volume of descriptive information and for lack of a necessary insight. One example was in the interpretation of light curves of long-period variables.

The shortest path to the essence of a problem is of course not always apparent. The best one can do is to look clearly at the facts as they seem to stand today, and try to see therein some key or pattern that could lead to true insight. This Colloquium is designed to lay before you some of these areas of stellar variability in which old topics are being re-examined from new directions. Let us hope that if there are any Newtons or Darwins in the audience they will require no more than this. 